\title{
REALIDADE, FANTASIA E ESCRITA LITERÁRIA NA NARRATIVA DER EINSIEDLER SERAPION, DE E.T.A. HOFFMANN
}

\author{
REALITY, FANTASY AND LITERARY WRITING IN E.T.A. HOFFMANN'S NARRATIVE DER \\ EINSIEDLER SERAPION
}

Beatriz Terreri Stervid ${ }^{1}$

RESUMO: Com a formulação do "princípio serapiôntico", a partir da narrativa Der Einsiedler Serapion (O eremita Serapião), E. T. A. Hoffmann estabelece diretrizes formais para sua prática literária que podem ser notadas em grande parte de sua obra. Tendo em vista as investigações entorno de uma "epistemologia literária”, em especial no âmbito da literatura alemã do início do século XIX, pretendemos analisar em que medida é possível considerar essa narrativa uma reflexão sobre a escrita literária, na qual se colocam em discussão os limites entre realidade e fantasia e, com isso, as relações entre literatura e conhecimento (Erkenntnis), de forma a participar da discussão epistemológica da época.

Palavras-chave: E. T. A. Hoffmann; princípio serapiôntico; epistemologia literária.

ABSTRACT: With the formulation of the "serapontic principle", based on the narrative Der Einsiedler Serapion, E. T. A. Hoffmann establishes formal guidelines for his literary practice that can be noticed in much of his work. Considering the investigations surrounding a "literary epistemology", especially in the context of the German Literature of the early 19th century, we intend to analyze to what extent it is possible to consider this narrative as a reflection on literary writing, in which the limits between reality and fantasy and the relations between literature and knowledge (Erkenntnis) are put in discussion, taking part in the epistemological discussion of the time.

Keywords: E. T. A. Hoffmann; serapiontic principle; literary epistemology.

\section{Introdução}

Com os esforços dos estudos literários concentrados primordialmente na busca pelo conhecimento sobre literatura, cabe a uma vertente, desenvolvida ao longo da segunda metade do século XX, a busca pela compreensão do conhecimento próprio da literatura. Entre os estudos que se dedicam às relações entre literatura e conhecimento encontram-se tanto aqueles que procuram compreender como o texto literário faz uso de conhecimentos provenientes de diversas áreas, quanto os que se propõem a investigar se o próprio processo de escrita pode ser considerado um processo de conhecimento (Erkenntnis) e qual seria a natureza desse conhecimento.

Porém, essas questões não se restringem à discussão de caráter científico, mas são objeto de ponderação também por parte de escritores, que na própria escrita literária abordam-nas

\footnotetext{
${ }^{1}$ Mestranda do Programa de Língua e Literatura Alemã do Departamento de Letras Modernas da Universidade de São Paulo-USP. Bolsista CAPES.
} 
direta ou indiretamente, questionando modelos de conhecimento propostos pela filosofia e, eventualmente, propondo modelos alternativos. Trata-se de escritores que

não somente se inscrevem dentro de um debate com diversos modelos oriundos da filosofia e da epistemologia das ciências, mas também (...) propõem modelos propriamente literários de uma teoria do conhecimento. É nesse sentido que escolhemos evocar uma 'epistemologia implícita' da literatura, que pode se constituir em referência aos modelos teóricos propostos dentro das ciências e da filosofia, mas que podem também seguir caminhos mais ecléticos (...) (MAILLARD, 2005, pp. 7-8, tradução nossa).

Segundo Kohlross (2010, p. 7), tais escritores que se inserem dentro de uma epistemologia literária buscam, através da própria literatura, compreender se ela não seria mais do que criação, mais do que expressão da imaginação por meio da língua, ou seja, se literatura se relaciona de alguma forma com a realidade. Os meios pelos quais essa discussão é realizada no texto literário são dos mais diversos, seja pela estrutura narrativa, pela caracterização das personagens ou nos diálogos entre elas.

A questão epistemológica foi tratada de forma recorrente nas obras literárias de escritores do final do século XVIII e início do século XIX, como Schiller, Kleist e Novalis. Justamente nesse período estava sendo desenvolvida na filosofia, em especial com Moritz e Kant, a reflexão sobre a autonomia da arte, o que acaba por possibilitar a discussão acerca da natureza da literatura e seu lugar em relação aos outros tipos de discurso. Verifica-se, assim, a tendência de diluição das fronteiras entre literatura e filosofia, atribuindo à primeira também um espaço de reflexão, em que é possível estabelecer uma racionalidade diferente daquela das ciências e do pensamento filosófico. Em diálogo com a filosofia da época, os textos literários podem estar inseridos na discussão epistemológica ao refletirem sobre a noção de conhecimento em relação às diversas áreas das ciências, bem como sobre a possibilidade de conhecimento na literatura.

Conhecido pelos seus contos fantásticos, E. T. A. Hoffmann (1776-1822) desenvolve em muitas de suas narrativas uma espécie de reavaliação da fantasia e imaginação, de forma a suspender, frequentemente, a oposição rígida entre razão e subjetividade. Na narrativa Der Einsiedler Serapion, a discussão sobre realidade e fantasia está ligada a uma reflexão mais direta sobre literatura, porquanto é através dessa narrativa que Hoffmann estabelece as diretrizes para sua prática literária, o que ficou conhecido sob o nome de "princípio serapiôntico" (Serapiontisches Prinzip).

Pretendemos, neste artigo, verificar em que medida é possível considerar essa narrativa uma reflexão sobre a escrita literária, na qual se colocam em discussão os limites entre realidade e fantasia e, com isso, as relações entre literatura e conhecimento. Também pretendemos investigar com quais estratégias literárias é feita essa discussão e como as respostas dadas pelo texto ajudam a configurar as diretrizes que irão exercer influência em grande parte de sua obra.

\section{Autorreflexão e epistemologia na literatura do romantismo alemão}

Em face da predominância, durante o século XVIII, do pensamento iluminista que 
tinha na razão um valor absoluto, coube ao romantismo rever esse valor e dar um novo sentido àquilo que foge do domínio da razão. Um dos principais pontos de unidade entre os românticos esteve na ênfase à imaginação e ao fantástico, a partir de um distanciamento (ou relativização) de princípios iluministas (cf. KREMER, 2007, p. 44). Assim, Friedrich Schlegel, em Conversa sobre a poesia (Gespräch über Poesie), concebe a poesia como um contraponto à racionalidade: "Pois este é o princípio de toda poesia, superar o percurso e as leis da razão racionalmente pensante e transplantar-nos de novo para a bonita confusão da fantasia" (SCHLEGEL, 1994, p. 55).

Porém, como aponta Pikulik (2000, p. 20-21), não se trata de uma oposição ao Iluminismo, muito menos de uma negação da razão, mas antes de uma autocrítica que procura ampliar o que se entende por racionalidade, sinalizando que ela não pode dar conta de toda a experiência humana, já que a "confusão da fantasia", inerente ao sujeito, também faz parte dessa experiência. Essa reavaliação da razão, e com ela a valorização da subjetividade, foi um dos fatores que impulsionaram a reflexão sobre as relações entre literatura e conhecimento:

(...) A criação da epistemologia literária como programa concorrente à teoria do conhecimento, que havia se emancipado da metafísica por volta de 1800 , tem suas bases quase concretas nas distinções, que nortearam Kant e as ciências modernas, entre pensar [Denken] e contemplar [Anschauen], assim como entre pensar e conhecer [Erkennen]. Pode ser inquestionável que nem toda contemplação seja um pensamento e nem todo pensamento seja também conhecimento. Mas será que, por conta disso, o que é criado pela imaginação poética deva ser considerado nada mais que um produto da fantasia, sobre o qual faz pouco sentido afirmar se é verdadeiro ou falso? E, não podendo ser fundamentado, por ser um produto da fantasia, significa que não pode ser também objeto de conhecimento [Wissen]? (KOHLROSS, 2010, p.13, tradução nossa).

Questionamentos como esses levaram escritores a refletirem sobre as possibilidades de conhecimento na literatura, reivindicando a ela também um espaço de pensamento intelectual. Assim, conceitos que até então pertenciam somente ao domínio da filosofia passaram também a ser abordados por meio de recursos estéticos. Com a presença, nos textos literários, de discussões antes realizadas somente por meio de procedimentos estritamente lógicos, os limites entre filosofia e literatura tornam-se mais difusos:

(...) por volta de 1800 , conceitos, sobre os quais a filosofia tinha exercido até então o poder de definição, começaram a ser reformulados com recursos estético-literários, por meio de textos [literários] que os exemplificavam de tal modo que não somente se podia estudar o uso (literal) dos conceitos, mas também transformá-los. Essa reformulação dizia respeito não só a conceitos como o Amor Romântico, mas também conceitos de origem filosófica como o do Sujeito ou da Imediação, assim como novos conceitos criados, como o da Estética, de modo que agora o conceito de Arte podia ser tratado também na arte, e não mais somente na filosofia (KOHLROSS, 2010, p. 12, tradução nossa). 
É assim que temos, nessa época, uma variedade de textos literários que tratam de questões relacionadas à estética, como, por exemplo, a obra conjunta de Wackenroder e Tieck, Herzensergießung eines kunstliebenden Klosterbruders (1797), em especial a narrativa Das merkwürdige musikalische Leben des Tonkünstlers Joseph Berglinger. Entre as questões presentes na obra destaca-se a discussão sobre a autonomia da arte, que estava sendo realizada no âmbito da filosofia. Também o conjunto de textos denominados Kreisleriana (1814-1815), de E .T. A. Hoffmann, são um exemplo da dissolução da fronteira entre os gêneros, mas especificamente entre literatura e crítica musical: o autor discute, através de procedimentos literários, problemas específicos de estética musical, impulsionando a formação de uma crítica realizada por meio da literatura.

Assim como essas duas obras citadas, há muitas outras cujos protagonistas são artistas, porquanto é principalmente por meio deles que é desenvolvida a reflexão (da arte) sobre arte. Podemos ainda citar, como exemplo, o romance Franz Sternbalds Wanderungen (1798) de Tieck, Heinrich von Ofterdingen (1802) de Novalis, Die lustigen Musikanten (1803) de Brentano, a narrativa Aus dem Leben eines Taugenichts (1826) de Eichendorff, o romance Lebens-Ansichten des Katers Murr (1819-1821) e o conto Ritter Gluck (1809) de E. T. A. Hoffmann, entre outros.

A autorreflexão da literatura também encontra respaldo na teoria desenvolvida por Friedrich Schlegel, em seus fragmentos. Ao defender, no fragmento 238 do Athenäum, uma "poesia transcendental", que, em analogia à "filosofia transcendental" de Kant, deveria refletir sobre suas próprias condições de possibilidade e "expor também a si mesma em cada uma de suas exposições e em toda parte ser, ao mesmo tempo, poesia e poesia da poesia” (1997, p. 89), coloca-se como proposta uma literatura que reflita sobre si mesma.

No domínio da epistemologia literária, como vimos, essa autorreflexão se encontra centrada especificamente nas relações da literatura com o conhecimento, podendo também abranger questões semelhantes que pressupõem uma discussão epistemológica, tal como a questão de como a literatura se relaciona com a realidade. Veremos, a seguir, como E. T. A. Hoffmann desenvolve, a partir da narrativa Der Einsiedler Serapion, uma reflexão sobre a escrita literária com base nessa questão.

\section{Realidade e fantasia em Der Einsiedler Serapion}

A narrativa Der Einsiedler Serapion está inserida na obra Die Serapionsbrüder, uma coletânea que reúne, em quatro volumes publicados entre 1819 e 1821, contos que, em sua maioria, já haviam sido originalmente publicados em diversos periódicos. À coletânea, E. T. A. Hoffmann acrescentou uma narrativa de moldura (Rahmenerzählung): quatro amigos, ligados por "uma mesma aspiração pela arte e ciência" (HOFFMANN, 2001, p. 14, tradução nossa)2, discutem questões relacionadas à literatura a partir de diversas narrativas contadas por eles, aparecendo como autores fictícios. Essa "moldura", que interliga os contos e dá coerência à ordenação, serve de espaço para comentários e reflexões sobre o material narrado.

\footnotetext{
${ }^{2}$ As traduções do texto de Hoffmann nas citações são de nossa autoria. $O$ texto original em alemão pode ser conferido também em: https://gutenberg.spiegel.de/buch/die-serapions-bruder-3106/3 (último acesso: 27 jul. 2019).
} 
Localizada no início da coletânea, Der Einsiedler Serapion não foi publicada individualmente, como a maioria das outras narrativas, mas foi concebida juntamente à narrativa de moldura. Ela é narrada por Cyprian, que, após explicar sua dificuldade em se desvencilhar da lembrança de "uma estranha aventura" vivenciada há vários anos, conta, por fim, essa aventura: o encontro com um homem que largara seu futuro brilhante de diplomata e a vida em sociedade para se instalar como eremita em uma floresta, convicto de ser Serapião, figura histórica do século IV. Suas fantasias eram contadas por ele com tamanha convicção que espantou profundamente o narrador Cyprian.

É justamente após ouvir a narrativa sobre o eremita que os amigos decidem contar suas histórias, tendo como base o "princípio serapiôntico": tudo deve ser narrado com a mesma convicção do eremita Serapião, de modo a passar aos ouvintes a certeza de o que se narra realmente aconteceu. Desse modo, a narrativa Der Einsiedler Serapion não somente tem a função de introduzir e fundamentar os contos da coletânea, mas também serve de base para postulação do princípio que norteia grande parte das obras do autor. Para que possamos compreender melhor esse princípio, bem como a reflexão sobre a escrita literária a ele subjacente, é necessário que antes analisemos a narrativa, em busca do entendimento de um dos alicerces dessa reflexão, a saber, a discussão sobre a realidade e a fantasia.

Em diversos pontos da narrativa encontramos uma oposição, posta pelo narrador, entre a realidade e a fantasia. Logo no início, ao descrever suas impressões do primeiro encontro com o eremita, ele diz:

A aparição toda tinha algo de estranho, de esquisito. Senti um leve arrepio passar pelo meu corpo. Mas também não se pode evitar tal sensação, se o que se viu somente em quadros ou se conheceu apenas através de livros aparece de repente na vida real. Lá estava sentado, vivo diante dos meus olhos, o anacoreta dos primórdios do Cristianismo, nas montanhas selvagens de Salvator Rosa (HOFFMANN, 2001, p. 24).

Para o narrador, é como se o eremita não pertencesse ao mundo real, mas sim ao da fantasia. Ele é comparado às imagens de quadros ou livros e, especificamente, às obras de Salvator Rosa, artista do século XVII que apresenta uma preferência pelas paisagens montanhosas, tal como no quadro "Paisagem com um eremita" (1665). Porém, o narrador convence-se, por fim, na tentativa de sair desse mundo fantástico e retornar à realidade, de que não há nada de anormal: "eu logo considerei que um monge viajante não seria algo nada extraordinário nessa região e, sem reserva, me aproximei do homem, perguntando-lhe como poderia, de maneira mais fácil, sair da floresta para retornar a $B^{* * * ”}(2001$, p. 24).

Entretanto, sua tentativa de voltar à esfera da realidade (e da racionalidade) é frustrada. Ao invés de indicar o caminho, Serapião lhe responde, mal-humorado, que havia sido interrompido na conversa com seus amigos, dentre eles Ambrosio de Camaldoli, outra figura histórica. Diante dessa resposta, o narrador comenta: "Era como se eu estivesse sonhando" (2001, p. 24).

Após esse primeiro encontro, o narrador procura descobrir mais sobre essa estranha figura, averiguando sobre o eremita com um camponês e mais tarde com um médico da cidade. 
O primeiro lhe explica apenas que se trata de um homem que "não bate bem da cabeça", mas que é amoroso e atencioso com os habitantes do vilarejo. Ao chegar à cidade, encontra o médico que, em suas palavras, lhe "esclareceu tudo" sobre o anacoreta (2001, p. 25). Isso indica não só sua necessidade de compreender tudo (ou de buscar conhecimento), mas também aponta para a figura do médico, ou do cientista, como aquele que detém o conhecimento e pode explicar a realidade através da razão.

Segundo o médico, tratava-se de um homem inteligente e sociável que, logo após terminar os estudos, recebera encargo importante de cunho diplomático, mas que desaparecera misteriosamente. Entretanto, outro atributo nos chama a atenção: ele também se dedicava à literatura e possuía um talento incomum: "Aos seus conhecimentos somava-se um excelente talento poético, tudo o que ele escrevia era animado por uma fantasia vívida, por um gênio singular que olhava na mais profunda profundeza" (2001, p. 25).

Sua aptidão para a literatura se mostrará, no decorrer na narrativa, a única característica em comum com aquele homem outrora integrado à sociedade. Assim, antes mesmo de se tornar um eremita, já pertencia, em algum grau, ao mundo da fantasia. Essa capacidade de "olhar na mais profunda profundeza" através da fantasia, ou seja, de enxergar além da realidade por meio da literatura, que era antes admirada por pessoas da sociedade como o médico, é levada a tal extremo que deixa de ser vista como um talento e passa a ser um sinal de loucura. Portanto, além da oposição entre realidade e fantasia, estabelece-se, de forma análoga, uma oposição entre razão e loucura.

Após um tempo desaparecido, ele volta à cidade, convicto de que é o eremita Serapião. Apesar das inúmeras tentativas de curá-lo de seu estado de loucura, internando-o em um hospício, ele volta a fugir e se instalar na floresta, onde o deixaram viver em paz. Dessa forma, as tentativas da ciência de compreender e explicar seu comportamento, como também de curálo através de terapias embasadas em teorias racionais, se mostraram todas fracassadas, o que indica uma falha da razão. Inconformado com essa falha, o narrador Cyprian decide ele mesmo tentar curar o eremita através da razão:

Eu tinha em mente nada menos que pegar a ideia fixa de Serapião pela raiz! Li Pinel, Reil, todos os livros possíveis sobre loucura que me chegavam às mãos. Acreditava que a mim, psicólogo espúrio, médico leigo, estivesse reservado jogar um raio de luz ao espírito entenebrecido de Serapião. Além desse estudo sobre a loucura, não deixei de me familiarizar com a história de todos os Serapiões, os quais existem na História dos Santos e Mártires nada menos que oito (HOFFMANN, 2001, p. 27).

Porém, mal iniciara sua "terapia de cura" e o eremita Serapião, que percebe a intenção de Cyprian, se defende da tentativa, afirmando ser constantemente procurado por pessoas que, "movidas pelo diabo, querem me convencer de que eu seja o Conte $\mathrm{P}^{* *}$ de $\mathrm{M}$-, para me levar ao orgulho e a todo tipo de má índole”. Afirma, então, que irá vencê-lo com "as armas da razão": “(...) O senhor é, claramente, o mais impotente de todos oponentes que já me apareceram e eu vou lhe combater com suas próprias armas, isto é, com as armas da razão” (2001, p. 30).

Segue, então, um longo monólogo, no qual Serapião usa de procedimentos da lógica para convencer Cyprian, primeiro, da inutilidade de tentar curá-lo, supondo que esteja 
realmente louco, e em segundo lugar, de que não é impossível que seja o mártir Serapião. Seu discurso, completamente moldado pelas “armas da razão", mostra ao interlocutor Cyprian que é possível defender "loucuras" através dela, o que mais uma vez indica uma falha do pensamento racional:

O senhor diz que o mártir Serapião viveu há muitos séculos e que, portanto, eu não poderia ser esse mártir, provavelmente porque seres humanos não podem viver por muito tempo na Terra. Em primeiro lugar, o tempo é um conceito tão relativo quanto o de número e eu poderia lhe dizer que, segundo o conceito de número que tenho dentro de mim, não se passaram nem três horas (ou seja lá qual for a maneira como o senhor queira designar o passar do tempo) que o Imperador Décio me fez ser executado. Mas, fora isso, suponhamos que o senhor possa agora se opor com a dúvida de que tal vida longa, que eu digo ter vivido, seja inédita e contrária à natureza humana. $\mathrm{O}$ senhor tem conhecimento da vida de cada pessoa que já existiu na Terra, de modo a conseguir dizer a palavra 'inédito' com confiança (HOFFMANN, 2001, p. 31).

Essa falha da razão se revela também no próprio conteúdo da fala de Serapião. Seguindo seu raciocínio, seria impossível provar a realidade, e com isso determinar o conhecimento, já que entre ser humano e mundo, há a subjetividade, que modela nossa percepção. Coloca-se, dessa forma, a impossibilidade de determinar o conhecimento, pois não é possível haver consenso sobre a realidade:

Mas digamos que eu lhe siga de fato até uma cidade que o senhor chama de $\mathrm{B}^{* * *}$, o senhor conseguiria me convencer que nós realmente andamos por duas horas e que o lugar em que chegamos realmente é $\mathrm{B}^{* * *}$ ? Se eu afirmar que o senhor, domado por uma loucura incurável, confunde o deserto tebano por um bosque e a longínqua Alexandria por uma cidade $\mathrm{B}^{* * *}$ no sul da Alemanha, o que o senhor poderia dizer? A velha briga não terminaria jamais e nos destruiria (HOFFMANN, 2001, p. 31).

Durante sua fala, o eremita mostra dominar os aspectos do discurso racional, o que não diminui, entretanto, sua loucura aos olhos de Cyprian, mas que o faz perceber a inutilidade de qualquer tentativa em curá-lo, já que a razão, dominada pelo próprio "louco", não terá nenhum efeito: "Com toda a minha sabedoria, diante deste louco estava estupefato - envergonhado! Com a conclusão do raciocínio de sua loucura, ele me levou ao chão e eu reconheci o tamanho da tolice de minha empreitada" (2001, p. 32).

Vimos, portanto, uma sequência de falhas da razão, inclusive na busca pelo conhecimento, já que ela não consegue explicar a realidade de forma satisfatória. A partir deste ponto da narrativa, Serapião defende que não existiria limite entre realidade e fantasia e que tudo seria realidade, ou seja, que a realidade é aquilo o que nós percebemos como tal:

Muitos também acharam isso inacreditável e disseram que eu apenas imagino ver o que de fato acontece diante de mim na vida externa e que isso se configura como criação de minha mente, de minha fantasia. Eu considero isso uma das mais capciosas bobagens que pode haver. Não é somente a mente que é capaz de apreender o que ocorre a nossa volta no tempo e espaço? O que 
ouve, vê e sente em nós? Serão talvez as máquinas mortas que nós chamamos de olho, ouvido, mão e etc. e não a mente? Será que a mente cria por conta própria, no íntimo, seu mundo condicionado pelo tempo e espaço e deixa aquelas funções ao encargo de outro princípio que habita dentro de nós? Que absurdo! Mas se é apenas a mente que apreende os eventos que ocorre à nossa frente, então realmente aconteceu o que ela reconhece (HOFFMANN, 2001, p. 35).

Para Serapião, a mente não cria, mas sim apreende a realidade. Essa certeza lhe dá, portanto, a convicção de que aquilo que ele vê acontece realmente, não duvidando nem por um momento da veracidade de suas visões. Em seguida, ele aplica esse pensamento à literatura, o que acaba por transferir essas reflexões ao âmbito da criação literária:

Ainda ontem falava Ariosto das imagens de sua fantasia e dizia que ele teria criado em seu íntimo figuras e acontecimentos que jamais existiram no tempo e espaço. Eu neguei que isso seja possível e ele teve que concordar comigo que é somente falta de conhecimento elevado se o poeta quer atribuir ao estreito espaço de seu cérebro tudo o que ele, por meio de sua faculdade especial de enxergar, vê vívido diante de si (HOFFMANN, 2001, p. 24).

Assim, a literatura não seria apenas mero produto da fantasia, mas estaria, ao contrário, em contato direto com a realidade, a qual o poeta enxerga de uma maneira especial e única, porquanto é através de sua mente que ele a apreende. Como ilustração do que acabara de explicar a Cyprian, o eremita narra uma história, a qual afirma ter se passado diante de si: "Deixe-me lhe contar o que aconteceu hoje diante de meus olhos, quando o sol nasceu e eu me encontrava no cume daquela montanha" (2001, p. 34). A narrativa de Serapião impressiona seu ouvinte, de maneira que ele também é levado a crer, pela magia em que é contada, na veracidade da história criada pelo eremita:

Serapião contava agora uma novela, criada e desenvolvida como somente o mais talentoso poeta com a mais vívida fantasia pode criar e desenvolver. Todas as formas se sobressaiam com contornos plásticos, com uma vida ardente, de modo que aquele que ouvia, arrastado, enfeitiçado por um poder mágico como em um sonho, tinha de acreditar que Serapião de fato vira, ele próprio, tudo de sua montanha. A essa novela seguiu-se outra e mais outra, até que o sol, alto, ao meio dia, se erguia sobre nós (HOFFMANN, 2001, p. 34).

Até então, Serapião era visto pelo narrador apenas como um louco, porém, após escutar suas narrativas, fica impressionado com seu talento para a literatura, e convence-se de sua genialidade: "tendo sua loucura metódica, na qual ele encontrou a salvação de sua vida, me trazido um profundo calafrio, estava pasmo com seu elevado talento poético; sua jovialidade, todo o seu ser, de uma calma abnegação do mais puro espírito, me comovia profundamente.” (2001, p. 35).

Com essa nova visão sobre Serapião, Cyprian coloca em dúvida os limites entre fantasia e realidade, loucura e racionalidade, de modo a fazer uma reavaliação da razão. Isso está posto de forma mais clara no texto através de uma citação, extraída de Hamlet, de uma fala de Ofélia: 
"eu vejo a mais nobre e elevada razão agora dissonante como sinos desafinados" ${ }^{3}$. Se antes confiava piamente na soberania do pensamento racional, simbolizado no texto pelo seu estudo da psiquiatria e sua tentativa de curar o eremita a partir de teorias científicas, agora estava fascinado pelo poder da literatura que, se criada com a convicção na realidade por detrás dela, é capaz de dissolver as fronteiras entre realidade e fantasia: ao mesmo tempo em que cria a partir da imaginação, enxerga o mundo real além do olhar comum, de modo a penetrar na "mais profunda das profundezas" da realidade:

Era de se admirar com que sagacidade, com que entendimento penetrante meu anacoreta falava sobre a vida em todas as suas configurações. Mais estranho era, porém, como ele desenvolvia acontecimentos históricos a partir de motivos profundos, totalmente divergentes de toda visão formada (HOFFMANN, 2001, p. 35-36).

Quando indagado por Cyprian sobre a veracidade dos fatos históricos apontados, já que "nenhuma obra histórica teria mencionado as circunstâncias especiais a que ele se referia”, o eremita responde que "(...) nenhum historiador no mundo poderia saber disso de forma tão precisa quanto ele, que teria escutado da boca das próprias pessoas atuantes, que o visitam" (2001, p. 36). É justamente a convicção de Serapião na veracidade do que narra, semelhante àquela que o levou à condição de eremita e, consequentemente, de loucura, o que dá às suas narrativas o entendimento profundo sobre a realidade. Dessa forma, paradoxalmente, o que distancia o eremita da realidade é, ao mesmo tempo, o que faz com que ele e seus ouvintes alcancem uma mais profunda compreensão sobre ela.

\section{A formulação do princípio serapiôntico}

Após Cyprian narrar a história sobre o eremita, os amigos relatam suas impressões. Dentre os comentários feitos, reitera-se algumas vezes o papel da subjetividade no olhar à realidade e, consequentemente, na construção da narrativa. Theodor aponta para o fato de que, mesmo que o poeta possa ser capaz de enxergar "nas profundezas mais lúgubres da natureza" (HOFFMANN, 2001, p. 37), ele não está isento à subjetividade no olhar, já que narra a partir das ideias e imagens que residem em seu interior: “(...) Admita apenas que, principalmente por terem se passado anos desde a última vez que você o havia encontrado vivo, você somente pode nos apresentar sua figura de forma clara a partir de como ela vive em seu interior" (2001, p. 37).

Ao Theodor contar, em seguida, a história do conselheiro Krespel (narrativa que recebeu o título de Rat Krespel) na tentativa de passar da loucura para "a razão completamente sã"4, Lothar faz um comentário semelhante, apontando para a participação dos gostos e interesses do poeta na constituição do material narrado: "Pode até ser que Cyprian tenha inconscientemente acrescentado algo de si à narrativa, mas você fez isso certamente muito mais, pois bem sei que tão logo a Música entra em cena, você entra em um estado sonâmbulo e tem as mais estranhas

\footnotetext{
${ }^{3}$ No texto de Hoffmann: “ (...) ich sehe die edle hochgebietende Vernunft, mißtönend wie verstimmte Glocken jetzt”. (Cf. Schakespeare: Hamlet, Ato III, Cena I)

4 "Ich möcht' euch davon erzählen, um den sanften Übergang vom Wahnsinn durch den Spleen in die völlig gesunde Vernunft zu bewirken” (HOFFMANN, 2001: 39).
} 
visões" (2001, p. 64-65). Em resposta a essa acusação, Theodor defende a veracidade dos fatos narrados, os quais ele mesmo teria testemunhado: "não teria eu falado de um fato que eu realmente vivenciei e se, caro Lothar, várias coisas lhe pareceram improváveis, então você deveria considerar que o que realmente acontece quase sempre é o mais improvável” (2001: 65).

Desse modo, tanto Cyprion quanto Theodor narraram algo que vivenciaram, mas são acusados de terem modificado a realidade dos fatos, na narrativa, a partir do olhar subjetivo. Porém, Lothar acrescentará, em seguida, que o que importa na literatura não é a veracidade do que se narra, mas a convicção nela:

Como se explica então a existência de várias obras poéticas que de forma alguma podem ser consideradas ruins, quanto à forma e à elaboração, mas que não suscitam efeito algum, como uma imagem descolorida (...). Como se explica isso senão pelo fato de que o poeta não viu realmente aquilo do que fala; que o fato, o acontecimento, representado diante de seus olhos com todo o ardor, espanto, júbilo e horror, não o animou, inflamou a ponto de que apenas as chamas interiores pudessem escapar em palavras vívidas: É inútil o esforço do poeta em nos fazer acreditar naquilo que ele próprio não acredita, não pode acreditar, porque ele não viu (HOFFMANN, 2001, p. 67).

Serapião é, então, considerado o melhor exemplo de um verdadeiro poeta, justamente porque podia narrar suas fantasias como se elas fossem realidade: "Cyprian, seu eremita era um verdadeiro poeta, ele tinha realmente visto o que ele pregava e, por isso, sua fala tinha coração e alma" (2001: 68). Lothar reflete então sobre o estado especial do eremita, cuja loucura, que o fazia acreditar naquilo que somente ele via, acabava por dissolver os limites do real e do fantástico. Tendo a convicção de Serapião como modelo, é sugerido que todos narrem contos de modo a fazer o ouvinte acreditar que os fatos narrados realmente aconteceram:

(...) cada um verifica se aquilo que vai narrar realmente foi visto, antes mesmo que ouse iniciar. Pelo menos, cada um se esforça sinceramente em apreender a imagem que surgiu dentro de si, com todas as suas formas, cores, luzes e sombras, e então, quando se sentir bastante inspirado, levar a imagem para a vida exterior. (...) O eremita Serapião é nosso santo padroeiro, ele exercerá sua visão sobre nós, seguiremos sua regra como fiéis irmãos Serapião! (HOFFMANN, 2001, p. 69).

Com base no discurso de Serapião, propõe-se que, para tornar vivas e convincentes as criações do poeta, produto de sua fantasia, ele deve senti-las e vê-las com nitidez dentro de si. Essa regra, chamada no texto de "princípio serapiôntico" (Serapiontisches Prinzip) ${ }^{5}$, é comentada e detalhada pelos amigos ao longo da coletânea, no interior da narrativa de moldura, tendo como ponto de partida as próprias narrativas, que devem, por sua vez, ter como base esse princípio.

Os aspectos do princípio serapôntico foram destacados e analisados principalmente no estudo de Pikulik (cf. RUTHNER, 2016, p. 121). Dentre os principais aspectos apontados por ele estão a verossimilhança, a credibilidade e a fidelidade aos detalhes, que estão ligadas ao aspecto da "verdadeira visão", extraído das discussões a partir da narrativa Der Einsiedler

\footnotetext{
5 "Verfängliche unseres Vereins, das der Teufel schon von selbst hineintragen wird, bei guter Gelegenheit, und sprechen wir von dem Serapionischen Prinzip! Was haltet ihr davon?" (2001, p. 70, grifo nosso).
} 
Serapion: "As imagens numa narrativa devem ser tão incorporadas, a ponto de não se reduzirem a simples reproduções, mas sim de apresentar imagens que realmente tenham sido vistas pelo interior de quem narra” (RUTHNER, 2016, p. 121).

Outro importante aspecto destacado diz respeito ao equilíbrio entre o "mundo interior", das criações da fantasia, e a realidade do "mundo exterior". Ele é elaborado a partir do comentário de Lothar, na narrativa de moldura, ao estado de loucura do eremita: "Pobre Serapião, do que consistia sua loucura a não ser do fato de que alguma estrela the havia roubado o conhecimento da duplicidade, do qual nosso ser terreno está inteiramente condicionado" (HOFFMANN, 2001, p. 68). Ele explica, então, que existiria em nós um "mundo interior" e uma força espiritual para vê-lo com clareza, porém seria o "mundo exterior" que colocaria, como uma alavanca, essa força em movimento. Ao eremita faltaria, portanto, o conhecimento desse mundo exterior:

Mas você, meu eremita, não estabeleceu nenhum mundo exterior, não viu a alavanca escondida, a força que age em nosso interior; e quando você afirmava, com terrível perspicácia, que é apenas a mente que vê, ouve, sente, compreende a ação e o acontecimento e, portanto, que realmente acontece aquilo que ela reconhece, você esqueceu que o mundo exterior força, arbitrariamente, a mente banida no corpo a essas funções da percepção (HOFFMANN, 2001, p. 68).

Serapião não admitia a separação do mundo exterior e do interior, ou seja, para ele esses dois mundos eram um só, o que fazia com que ele não tivesse em si essa duplicidade da qual fala Lothar. Portanto, o aspecto mencionado consiste do reconhecimento da existência dessa duplicidade (mundo interior e mundo exterior) e a busca pelo equilíbrio entre esses dois opostos: "O poeta que se prende apenas ao mundo interior tende à loucura, e aquele que vive somente a realidade do mundo exterior tende a banalizar a própria vida, contudo, a razão não deve suplantar a fantasia, 'o cálculo racional não pode sufocar a visão interior"” (RUTHNER, 2016, p. 121).

Dessa forma, a partir das discussões suscitadas pela narrativa Der Einsiedler Serapion sobre a escrita literária e suas relações com a realidade e fantasia, Hoffmann elabora diretrizes estéticas que irão exercer influência não só nos contos dessa coletânea, mas também em suas outras obras, como aponta Brown:

O "Erkenntnis der Duplizität" [conhecimento da duplicidade] de Lothar, por exemplo, enraizado filosoficamente como no dualismo primário entre sujeito e objeto, conduz diretamente, através do "Erkenntnis" [conhecimento] deste estado de dualidade das coisas, à adoção de uma postura irônica (o que o próprio Hoffmann denominou "eine durchgehaltene Ironie"). Seja em uma veia humorística ou uma mais séria, essa é uma característica de praticamente toda a obra literária de Hoffmann (BROWN, 2006, p. 185, tradução nossa).

\section{Considerações finais}

Como buscamos demonstrar, Hoffmann discute, através da elaboração do princípio 
serapiôntico, sobre os limites e as relações entre realidade e fantasia na escrita literária. Essa discussão, tanto no âmbito da narrativa Der Einsiedler Serapion quanto nos diálogos inseridos na narrativa de moldura, pode ser considerada uma autorreflexão da literatura sobre seus próprios limites, bem como sua relação com o mundo real.

Coloca-se, primeiramente, a possibilidade de dissolução, através da literatura, dos limites entre realidade e fantasia (responsável pela convicção naquilo que se narra), e, posteriormente, a partir das considerações inseridas na narrativa de moldura, a necessidade de equilíbrio entre essas duas esferas, como também entre racionalidade e imaginação.

Por fim, ao discutir essas questões, Hoffmann reflete sobre a posição da literatura, atribuindo a ela também um espaço de reflexão filosófica. $O$ princípio serapiôntico revela-se uma proposta de considerar a literatura um olhar criativo, condicionado pela subjetividade, mas que é capaz de enxergar além do que é normalmente percebido pelo olhar não poético, justamente por trazer à tona aquilo que era ignorado pela racionalidade da filosofia e das ciências: a imaginação.

\section{Referências}

BROWN, H. E. T. A. Hoffmann and the Serapiontic Principle: Critique and Creativity. Nova York: Camden House, 2006.

KOHLROSS, C. Die poetische Erkundung der wirklichen Welt: Literarische Epistemologie (1800-2000). Bielefeld: Transcript Verlag, 2010.

KREMER, D. Romantik. Lehrbuch Germanistik. Stuttgart/ Weimar: J.B. Metzler, 2007.

MAILLARD, C. Littérature et théorie de la connaissance/ Literatur und Erkenntnistheorie 1890-1935. Estrasburgo: Presses Universitaires De Strasbourg, 2004.

PIKULIK, L. Frühromantik. Epoche - Werke - Wirkung. München: C. H. Beck, 2000.

RUTHNER, S. M. A dimensão ecfrástica nos contos de E. T. A. Hoffmann: Um estudo propedêutico para a abordagem das narrativas musicais. Dissertação de Mestrado, Universidade Estadual do Rio de Janeiro, Rio de Janeiro, 2016.

SCHLEGEL, F. Conversa sobre a poesia e outros fragmentos. Tradução de Victor-Pierre Stirnimann. São Paulo: Iluminuras, 1994.

SCHLEGEL, F. O dialeto dos fragmentos. Tradução de Márcio Suzuki. São Paulo: Iluminuras, 1997.

HOFFMANN, E. T. A. Die Serapionsbrüder. Frankfurt am Main: Deutscher Klassiker Verlag, 2001.

Recebido em: 27/07/2019

Aceito em: 24/09/2019 